\title{
Protective STA-MCA bypass to prevent brain ischemia during high-flow bypass surgery: case series of 10 patients
}

\author{
Christopher J. Stapleton ${ }^{1} \cdot$ Fady T. Charbel ${ }^{1}$
}

Received: 8 April 2019 / Accepted: 9 April 2019 / Published online: 19 April 2019

(C) Springer-Verlag GmbH Austria, part of Springer Nature 2019

Aboukais et al. present an article titled "Protective STA-MCA bypass to prevent brain ischemia during high-flow bypass surgery: case series of 10 patients." [1] Using data from two institutions, the authors report the strategy of performing a STA-MCA bypass prior to completing a "high-flow" ECAMCA bypass utilizing an interposition ulnar vein graft (UVG) for the purpose of flow replacement during aneurysm surgery. The cohort included 5 patients with ICA aneurysms ( 3 cavernous/paraclinoid, 1 terminus, 1 not specified), none of whom tolerated a balloon occlusion test or had anatomy suitable for placement of a flow diverter, and 5 with MCA bifurcation aneurysms. Mean total surgical time was $11 \mathrm{~h}$ (range 9$12 \mathrm{~h}$ ). The mean recipient vessel occlusion time was $42 \mathrm{~min}$ (range 30-70 $\mathrm{min}$ ) for STA-MCA bypasses and $51 \mathrm{~min}$ (range 37-65 $\mathrm{min}$ ) for ECA-UVG-MCA bypasses. In addition to the STA-MCA and ECA-UVG-MCA bypasses, 2 patients underwent M2 MCA-M2 MCA bypasses. In total, 7 singleand 3 double-barrel STA-MCA bypasses were performed. Following creation of the bypasses, 7 patients underwent surgical parent artery occlusion while 3 patients underwent postbypass endovascular parent artery occlusion. The authors did not perform intra-operative blood flow measurements nor did they utilize intra-operative neurophysiologic monitoring. Early ( $<7$ days) angiographic follow-up showed patency of all bypasses except 1 ECA-UVG-MCA bypass and no patients had any new areas of restricted diffusion on postoperative MR imaging, when performed. Modified Ranking Scale (mRS) scores at 90 days improved from baseline in 1 patient, remained the same in 7 patients, and worsened in 2

This article is part of the Topical Collection on Vascular Neurosurgery Aneurysm

Fady T. Charbel

fcharbel@uic.edu

1 Department of Neurosurgery, Neuropsychiatric Institute (MC 799), University of Illinois at Chicago, 912 South Wood Street, Rm 451N, Chicago, IL 60612-5970, USA patients, 1 of whom died secondary to an ICA dissection that led to a hemispheric infarction. The authors conclude that a "protective" STA-MCA bypass can reduce the risk of ischemic complications associated with high-flow bypass surgery. However, the authors do not include data from a control cohort of patients that did not undergo STA-MCA bypass to demonstrate that the risk of "high-flow" ECA-MCA bypass alone is unacceptably high.

While revascularization procedures remain a critical and necessary part of cerebrovascular surgery, recent data indicates that bypass for the purpose of flow replacement during aneurysm surgery has steadily declined [6, 10], likely reflecting greater utilization of novel endovascular technologies. Therefore, in this endovascular era, indications for bypass must be sound and the procedures must be performed in the safest manner possible. It is essential to keep in mind that a bypass in the context of aneurysm surgery is a flow replacement bypass, in which the sole purpose of revascularization is replacement of the flow deficit caused by treatment of the aneurysm $[2,7]$. In this regard, we base our intra-operative decisions according to real-time cerebral blood flow measurements in a systemic, algorithmic manner. With this "flowassisted surgical technique" (FAST) [2, 3, 5, 9], the debate is less about the utility of a "protective" STA-MCA bypass, but rather about how much flow the ECA-MCA bypass should provide and, at times, whether an interposition graft is even necessary.

The following represents our flow-assisted algorithm. For proximal ICA aneurysms (i.e., cavernous or paraclinoid), flow in the distal ICA or M1 MCA is measured before and after temporary ICA occlusion (typically of the cervical ICA), which reveals the flow deficit or, in other words, the amount of blood flow the bypass must replace. In patients with large ACoA and/or PCoA, the native collateral flow can be great and, as a result, the flow deficit may be small. Depending on its carrying capacity, the STA may provide adequate flow replacement. This is assessed by measuring the cut flow [4, 8]. If the cut flow can compensate for the calculated flow 
deficit, then a STA-MCA bypass alone is performed, without need for a separate bypass with an interposition graft. If the cut flow is insufficient to replace the flow deficit, then an interposition graft (either saphenous vein or radial artery) is used and is anastomosed either to the stump of the STA or the ECA proper. After completing the bypass and occluding the relevant parent artery, flow is measured in the graft to confirm adequate replacement.

For complex aneurysms at the ICA terminus, MCA, or PICA, direct flow measurements of the vessels at risk of compromise are used to determine the distal flow replacement requirements. The decision to perform a double-barrel STAMCA bypass or a STA-MCA bypass plus an intracranialintracranial (e.g., M2 MCA-M2 MCA) bypass is, therefore, based on an assessment of flow. Overall, we believe this technique provides a mechanism for guiding graft selection to provide optimal revascularization while minimizing anesthesia and temporary clipping time [9].

For all flow replacement procedures, we routinely use intra-operative neurophysiologic monitoring. All anastomoses are performed with the patient in burst suppression and induced hypertension, in an effort to augment collateral supply, can be used if a reduction in SSEPs or MEPs is detected. In our experience with this technique, we have often found that a STA-MCA bypass itself is sufficient to revascularize the territories in need of flow replacement. With the use of surgical adjuncts such as neurophysiologic monitoring and induced hypertension, we have also found that most patients tolerate ECA-MCA bypass with an interposition graft without the need for a "protective" STA-MCA bypass.

\section{References}

1. Aboukais R, Verbraeken B, Leclerc X, Gautier C, Vermandel M, Bricout N, Lejeune J-P, Menovsky T (2019) Protective STA-MCA bypass to prevent brain ischemia during high-flowbypass surgery: case series of 10 patients. Acta Neurochir

2. Amin-Hanjani S, Alaraj A, Charbel FT (2010) Flow replacement bypass for aneurysms: decision-making using intraoperative blood flow measurements. Acta Neurochir 152:1021-1032; discussion 1032. https://doi.org/10.1007/s00701-010-0635-4

3. Amin-Hanjani S, Charbel FT (2007) Flow-assisted surgical technique in cerebrovascular surgery. Surg Neurol 68(Suppl 1):S4-S11. https://doi.org/10.1016/j.surneu.2007.07.051

4. Amin-Hanjani S, Du X, Mlinarevich N, Meglio G, Zhao M, Charbel FT (2005) The cut flow index: an intraoperative predictor of the success of extracranial-intracranial bypass for occlusive cerebrovascular disease. Neurosurgery 56:75-85 discussion 75-85

5. Ashley WW, Amin-Hanjani S, Alaraj A, Shin JH, Charbel FT (2008) Flow-assisted surgical cerebral revascularization. Neurosurg Focus 24:E20. https://doi.org/10.3171/FOC/2008/24/2/ E20

6. Burkhardt JK, Lawton MT (2019) Practice trends in intracranial bypass surgery in a 21-year experience. World Neurosurg doi: https://doi.org/10.1016/j.wneu.2019.01.161

7. Charbel FT, Guppy KH, Ausman JI (2006) Cerebral revascularisation: superficial temporal middle cerebral artery anastomosis. Atlas of neurosurgical techniques. In: Thieme medical publishers. Stuttgart, Germany

8. Charbel FT, Meglio G, Amin-Hanjani S (2005) Superficial temporal artery-to-middle cerebral artery bypass. Neurosurgery 56:186190 discussion 186-190

9. Rustemi O, Amin-Hanjani S, Shakur SF, Du X, Charbel FT (2016) Donor selection in flow replacement bypass surgery for cerebral aneurysms: quantitative analysis of long-term native donor flow sufficiency. Neurosurgery 78:332-341; discussion 341-332. https://doi.org/10.1227/NEU.0000000000001074

10. Winkler EA, Yue JK, Deng H, Raygor KP, Phelps RRL, Rutledge C, Lu AY, Rodriguez Rubio R, Burkhardt JK, Abla AA (2019) National trends in cerebral bypass surgery in the United States, 2002-2014. Neurosurg Focus 46:E4. https://doi.org/10.3171/2018. 11.FOCUS18530

Publisher's note Springer Nature remains neutral with regard to jurisdictional claims in published maps and institutional affiliations. 